\title{
38. PALEOMAGNETIC AND ROCK-MAGNETIC STRATIGRAPHY OF PIGMY BASIN, DEEP SEA DRILLING PROJECT SITE 619, LEG 96 ${ }^{1}$
}

\author{
John W. King, University of Rhode Island ${ }^{2}$
}

\begin{abstract}
A high-resolution paleomagnetic record for the late Pleistocene has been obtained from the upper $146 \mathrm{~m}$ of the Pigmy Basin section recovered at Deep Sea Drilling Project Site 619. The record is characterized by a sequence of apparent geomagnetic excursions. If validated by future investigations, these excursions can be used to construct a regional highresolution stratigraphic framework for the Gulf of Mexico. Variations in the rock-magnetic stratigraphy of Pigmy Basin are shown to correspond to variations in lithology. These observed variations probably reflect a combination of regional and local paleoenvironmental changes.
\end{abstract}

\section{INTRODUCTION}

Previous studies of the paleomagnetic record preserved in rapidly deposited sediments from the Gulf of Mexico (Clark and Kennett, 1973; Freed and Healy, 1974) have identified at least two possible geomagnetic excursions during the late Pleistocene. If a sequence of these paleomagnetic excursions can be identified and validated as geomagnetic features, it will then be possible to construct a high-resolution geomagnetic stratigraphic framework for Pleistocene sedimentation in the Gulf of Mexico. A major goal of this investigation was to test the feasibility of constructing this framework by detailed paleomagnetic studies of Hole 619 drilled in Pigmy Basin during Deep Sea Drilling Project (DSDP) Leg 96 (see Site 619 chapter, this volume). This attempt should be labeled as a feasibility study because the methodological requirements for constructing a high-resolution geomagnetic stratigraphic framework are not met by the cores collected from Hole 619. These requirements are that the cores be free of twisting, azimuthally and vertically oriented, and that complete replicate sections be available for study.

Rock-magnetic measurements are defined in this chapter as those relating to the mineral properties of marine sediments, whereas paleomagnetic measurements relate to the natural remanence properties. One goal of the rock-magnetic portion of this study was to provide information on the mineral-magnetic properties of the sediments relevant to the interpretation of the paleomagnetic data. Recent work (Kent, 1982; Bloemendal, 1983; Robinson, 1986) indicates that rock-magnetic measurements are also useful for detecting climatically induced changes in the magnetic properties of marine sediments. Therefore, a second goal of the rock-magnetic study was to identify and characterize paleoenvironmental changes in Pigmy Basin.

\footnotetext{
${ }^{1}$ Bouma, A. H., Coleman, J. M., Meyer, A. W., et al., Init. Repts. DSDP, 96: Washington (U.S. Govt. Printing Office).

2 Address: Graduate School of Oceanography, University of Rhode Island, Narragansett, RI 02882-1197.
}

\section{SAMPLING AND MEASUREMENTS}

The hydraulically piston cored $208.7 \mathrm{~m}$ section of late Pleistocene clays recovered at Site 619 was sampled at 20 -cm intervals to a depth of $177.4 \mathrm{~m}$ by the staff of Leg 96 on board the Glomar Challenger. Two $5-\mathrm{cm}^{3}$ samples were obtained at each level using a hand sampling device. Orientation was maintained by placing the split $1.5-\mathrm{m}$ working section of core in a $1.5-\mathrm{m}$ aluminum gutter, and pushing the hand sampling device through an orientation jig that rested on the sides of the gutter. A pair of samples was taken at each level with one sample away from the split face and one adjacent to the split face, in a vertical stacking arrangement. Following the cruise, sample pairs were also obtained at the DSDP East Coast Core Repository; these pairs were aligned side by side, and equidistant from the core liner and the split face. These two different sampling schemes were intended to test the effect of the splitting process on the natural remanent magnetization (NRM) of the sediment.

The NRM of the samples was measured with a two-axis cryogenic magnetometer. Step-wise alternating field (AF) demagnetization of pilot pairs with a Schonstedt demagnetizer indicated that 100 Oe was the optimum blanket field for demagnetizing the samples (see Figs. 1-3). All samples were therefore demagnetized to at least $100 \mathrm{Oe}$ and then remeasured. After the NRM measurements were completed, the rockmagnetic measurements were made. The following methods were used for the measurements: (1) low-field susceptibility $(\chi)$ was measured on a Bartington bridge with a sensitivity of $\sim 5 \times 10^{-7} \mathrm{G} / \mathrm{Oe}$, and (2) an anhysteretic remanent magnetization (ARM) was imparted, after demagnetizing the samples at 1000 Oe by placing the samples in a $0.5 \mathrm{Oe}$ DC field and applying a 1000 Oe peak AF field. The ARM values were measured on the cryogenic magnetometer.

\section{RESULTS}

\section{Paleomagnetic Results}

A total of 150 sample pairs were step-wise AF demagnetized at levels of $0,100,200,400$, and in some instances $600 \mathrm{Oe}(10 \mathrm{Oe}=1 \mathrm{mT})$. Representative $\mathrm{Zij}$ derveld (1967) and demagnetization plots are shown in Figures 1-3. The data in Figures 1 and 2 are representative of the sediments between 0 and $146 \mathrm{~m}$ sub-bottom and indicate that the magnetizations are stable between 100 and 400 Oe and are reproducible at the same horizon. The data in Figure 3 are representative of the sediments below $146 \mathrm{~m}$ sub-bottom and indicate that the magnetizations are stable between 100 and $400 \mathrm{Oe}$, but are not reproducible at the same horizon. Overall, the demagnetization studies of pilot samples indicated that 
A
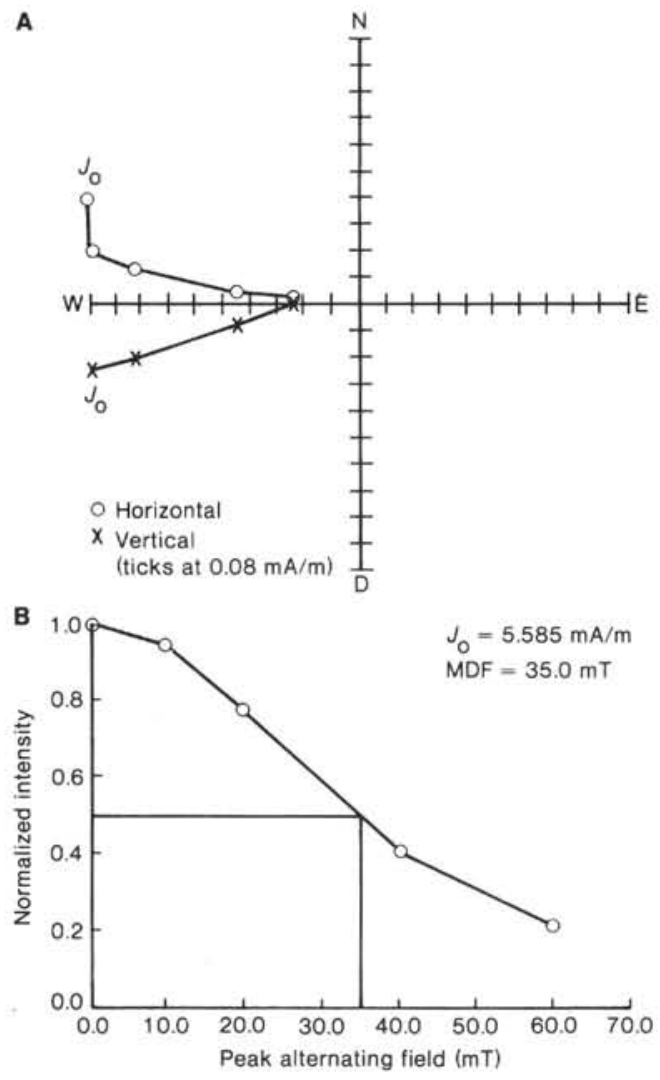
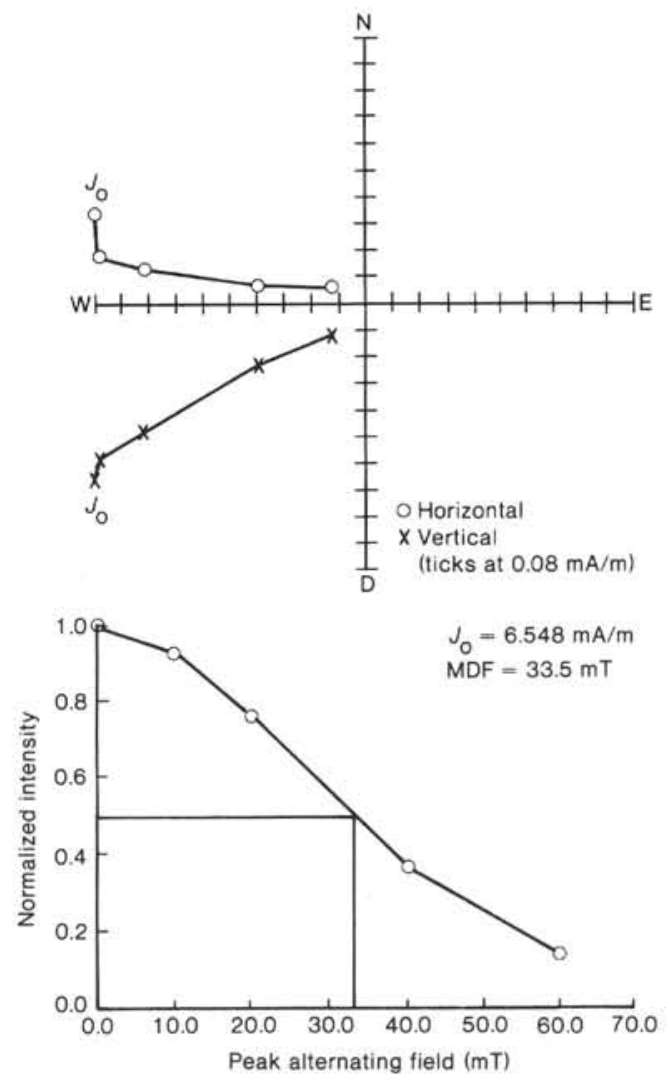

Figure 1. A. Zijderveld plots of two samples from $18.54 \mathrm{~m}$ sub-bottom in Hole 619 , Pigmy Basin $(1 \mathrm{mT}=10$ Oe and $1 \mathrm{~mA} / \mathrm{m}=10^{-6} \mathrm{G}$ ). B. Demagnetization plots of the same samples. (MDF = median destructive field).

A
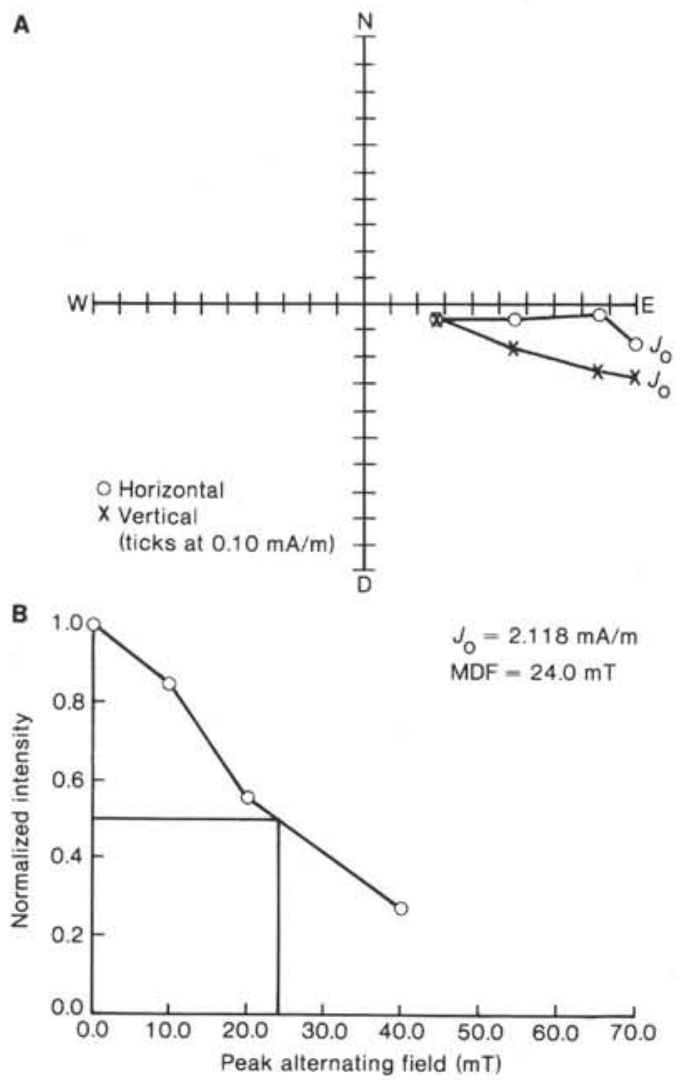
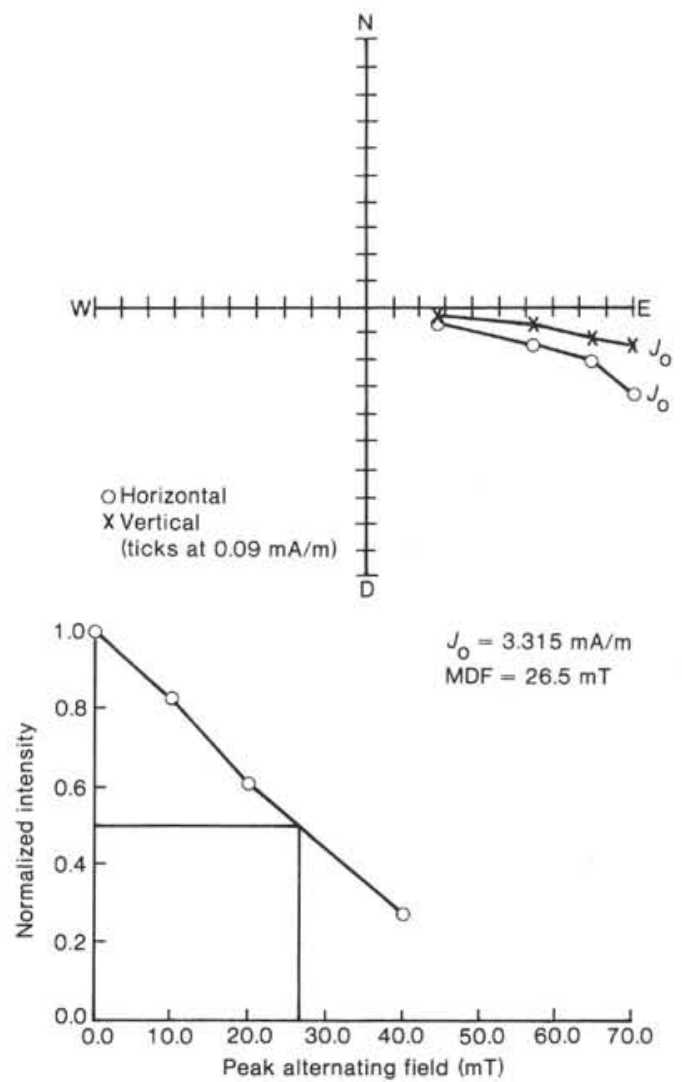

Figure 2. A. Zijderveld plots of two samples from $34.11 \mathrm{~m}$ sub-bottom in Hole 619, Pigmy Basin (1 mT = 10 Oe and $1 \mathrm{~mA} /$ $\mathrm{m}=10^{-6} \mathrm{G}$ ). B. Demagnetization plots of the same samples. 
A
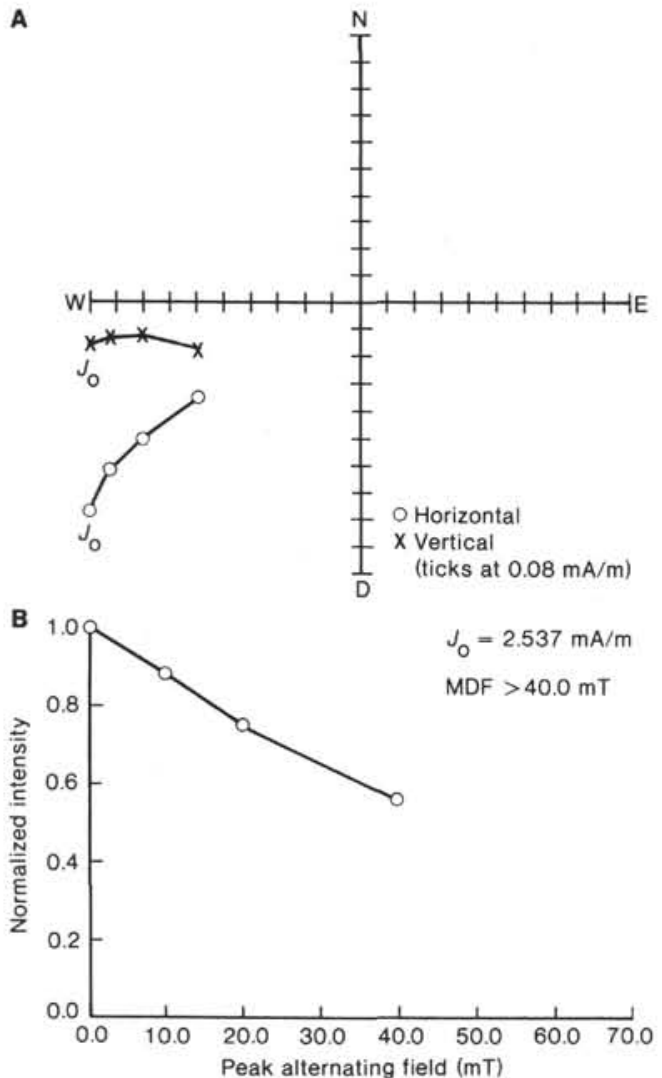
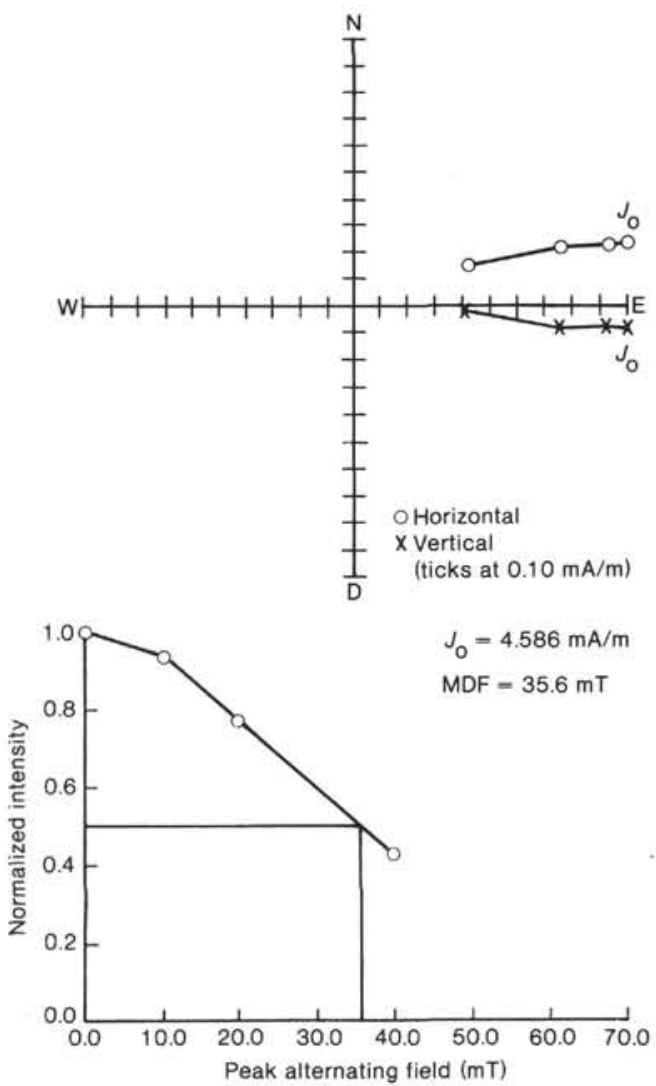

Figure 3. A. Zijderveld plots of two samples from $146.31 \mathrm{~m}$ sub-bottom in Hole 619, Pigmy Basin ( $1 \mathrm{mT}=10$ Oe and $\left.1 \mathrm{~mA} / \mathrm{m}=10^{-6} \mathrm{G}\right)$. B. Demagnetization plots of the same samples.

it was possible to obtain optimal results with a blanket AF treatment of 100 Oe.

The stratigraphies of inclination $\left(I_{100}\right)$, declination $\left(D_{100}\right)$ and intensity of the magnetic moment $\left(M_{100}\right)$, AF demagnetized at $100 \mathrm{Oe}$, are shown in Figure 4. The reproducibility of the results indicated by the difference in the values for the two samples per stratigraphic level is good down to $146 \mathrm{~m}$ sub-bottom depth. Below this depth, the results at a given level are not very reproducible, and the average difference between the paired samples is often greater than $60^{\circ}$.

The cores were not azimuthally oriented and in some instances (e.g., Cores 619-3 and -13) they appear to be twisted. These factors severely limit the utility of the declination stratigraphy for detecting possible geomagnetic excursions. Therefore, the inclination stratigraphy provides the best evidence for possible geomagnetic excursions. The general pattern of variation in inclination (in the upper $146 \mathrm{~m}$ of the section) is best described as longer intervals of minor fluctuations about a positive value punctuated by shorter excursions to low positive or negative values. In addition, the inclination values approximate axial dipole values in the upper part of the section $(0-35 \mathrm{~m})$ and tend to shallow with depth to $146 \mathrm{~m}$. The inclination results below $146 \mathrm{~m}$ are not very reproducible, both within and between levels, and they probably do not record geomagnetic features.

The paleomagnetic excursion that occurs within the interval 13.7-19.1 m sub-bottom is examined in detail in Figure 5A. The pattern of $I$ and $D$ fluctuations is very similar to that observed in the Mono Lake record in the interval that includes the Mono Lake excursion (Liddicoat and Coe, 1979; Fig. 5B). However, it is not possible to equate the two records until the paleomagnetic record of Pigmy Basin is demonstrated to be reproducible and better time control is provided by other investigations.

A comparison of the results obtained by the two different sampling methodologies of the interval 16.58$21.57 \mathrm{~m}$ is shown in Table 1 . The sample pairs taken 0.5 $\mathrm{cm}$ below the split face of the core in a side-by-side arrangement produced significantly better results than those obtained in a vertical arrangement with one sample adjacent to the split face.

\section{Rock-Magnetic Results}

The variation with depth of low-field susceptibility $(\chi), A R M$, and $A R M / \chi$ is shown in Figure 6. Variations in $\chi, \mathrm{ARM}$, and ARM $/ \chi$ are dependent on the concentration and characteristics of the magnetic minerals contained in the sediments. Isothermal remanent magnetization (IRM) acquisition curves (Fig. 7) indicate that the dominant magnetic mineral in the Pigmy Basin sediments is magnetite. Therefore variations in $\chi, \mathrm{ARM}$, and ARM/ $\chi$ at Pigmy Basin are primarily a function of concentration and particle-size variation in magnetite. Low-field susceptibility is slightly biased toward coarse-grained magnetite (King et al., 1982), but the variation of this parameter is primarily a function of magnetite concentration. ARM is strongly biased toward fine-grained magnetite (King et al., 1982), therefore the variation of this 


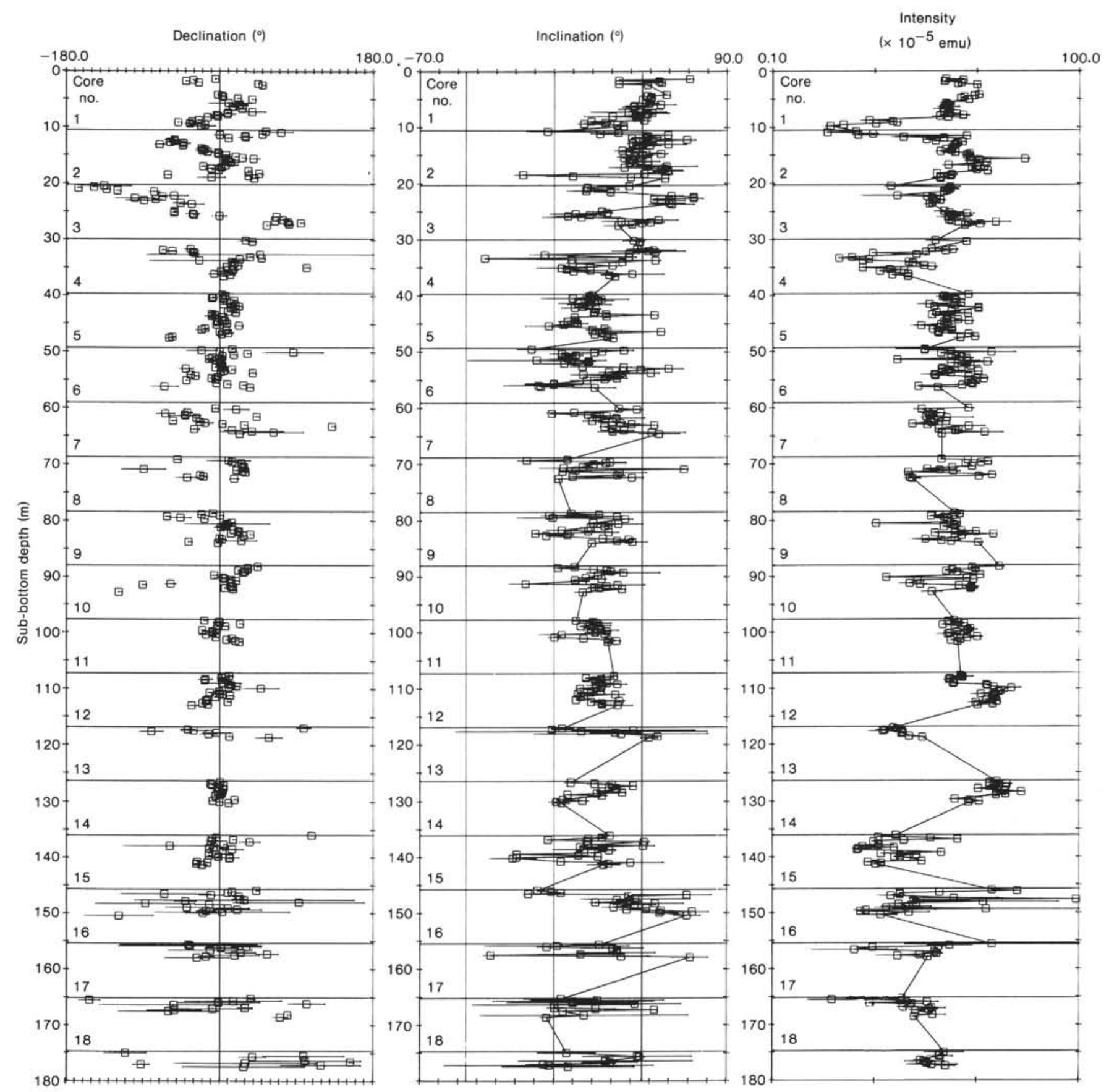

Figure 4. Plots of the declination $\left(D_{100}\right)$, inclination $\left(I_{100}\right)$, and intensity of magnetic moment $\left(M_{100}\right)$ after AF demagnetization at 100 Oe versus depth at Pigmy Basin. The squares are the mean value of two samples per level and the range is indicated by error bars. Core boundaries are indicated by the horizontal grid. The declination record is constructed by determining the mean $D$ for each section, normalizing the mean to zero, and then plotting the value about the mean. The inclination and intensity plots show the raw data.

parameter is a function of both particle-size and concentration. The ratio of $\mathrm{ARM} / \chi$ normalizes for concentration variations and is primarily a function of particlesize variation in magnetite. High values of $\mathrm{ARM} / \chi$ indicate the presence of fine-grained magnetite, whereas low values indicate the presence of coarse-grained magnetite (King et al., 1982). The relative particle-size variations of magnetite can often be used as an analog for grainsize variations of the total sediment.

The $\chi$ and ARM stratigraphies indicate relatively low magnetic concentrations in the $\mathrm{Z}$ and upper $\mathrm{Y}$ Ericson zones (Ericson and Wollin, 1968) between 0 and $40 \mathrm{~m}$ sub-bottom, higher concentrations in the lower Y zone between 40 and $135 \mathrm{~m}$, and lower concentrations at the base of the $\mathrm{Y}$, and in the $\mathrm{X}$ and $\mathrm{X}$ ? zones below $135 \mathrm{~m}$ (Fig. 6; Kohl, this volume). The most distinctive features of the ARM $/ \chi$ stratigraphy are (1) deposition of relatively fine magnetite between 0 and $5.0 \mathrm{~m}$ sub-bottom in Zone Z, (2) deposition of coarser magnetite during the transition from $\mathrm{Z}$ to $\mathrm{Y}$ between 5.0 and $8.7 \mathrm{~m}$, (3) deposition of very coarse magnetite during the termination of Zone Y between 8.7 and $11.5 \mathrm{~m}$ sub-bottom, (4) an 
A

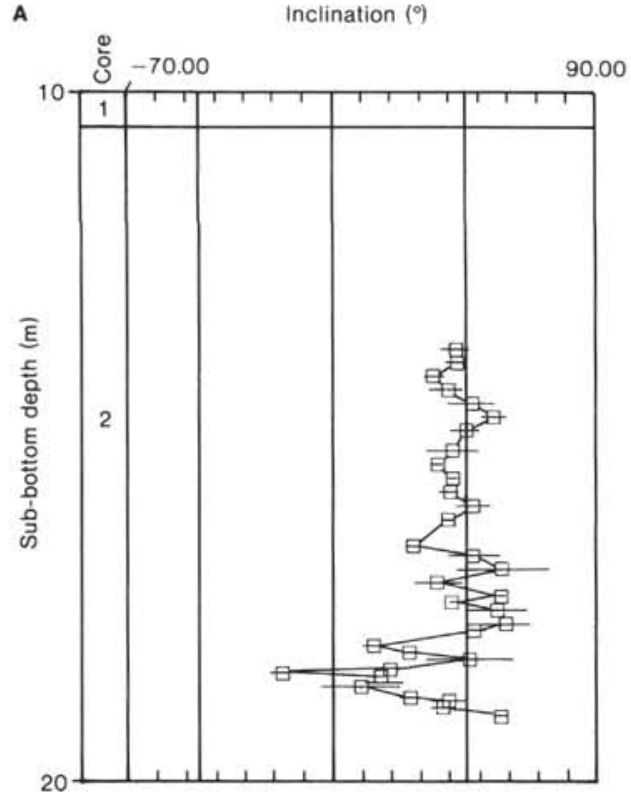

B

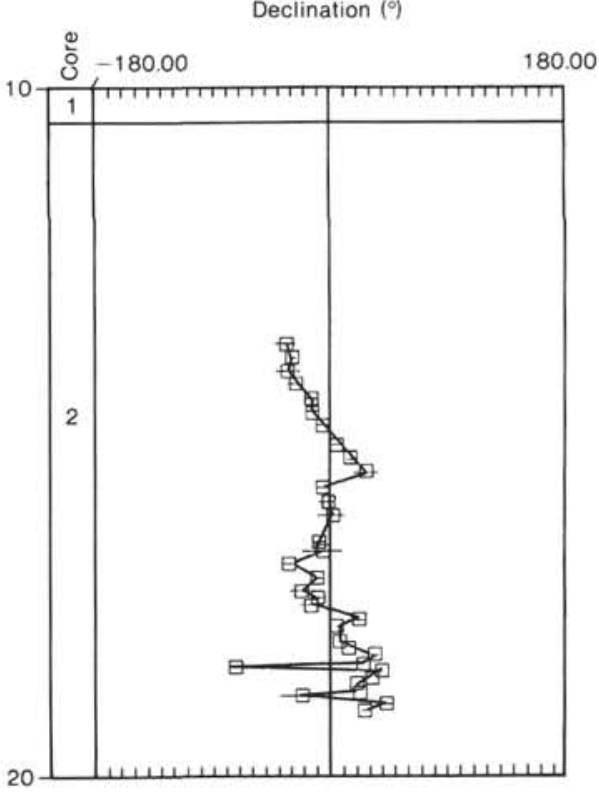

Declination $\left({ }^{\circ}\right)$
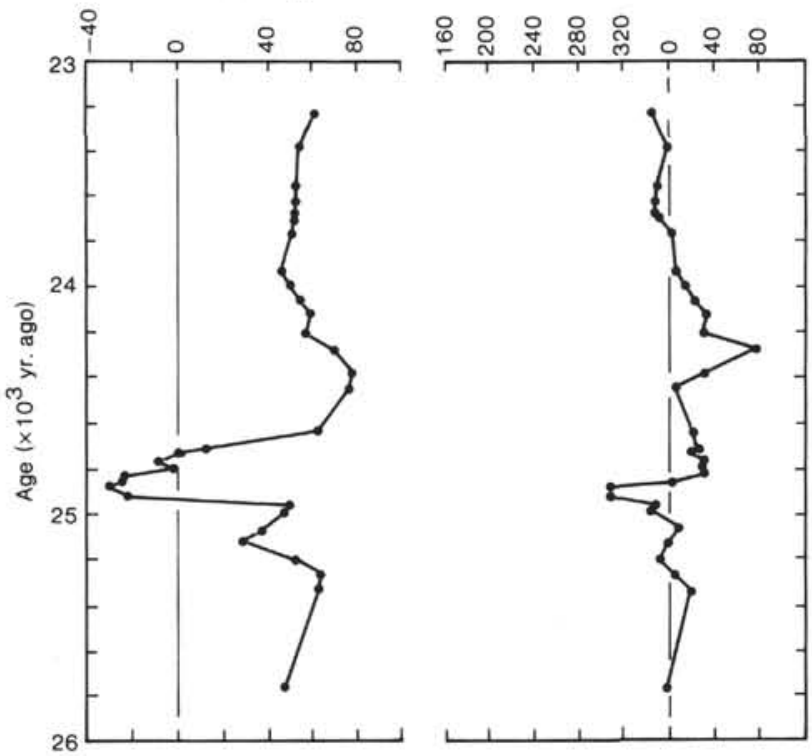

Figure 5. A comparison of the AF demagnetized inclination and declination record of (A) Pigmy Basin for the interval 13.7-19.1 m sub-bottom and (B) the record of Mono Lake, California (Liddicoat and Coe, 1979) adjacent to and including the Mono Lake excursion.

Table 1. Comparison of NRM results obtained by the two different sampling methods used in this study for the interval 16.58-21.57 m sub-bottom depth.

\begin{tabular}{ccc}
\hline & $\begin{array}{c}\text { Average difference between } \\
\text { vertically stacked paired } \\
\text { subsamples, one sample } \\
\text { contains the split face } \\
\text { (16 pairs) }\end{array}$ & $\begin{array}{c}\text { Average difference between } \\
\text { side-by-side paired sub- } \\
\text { samples, both samples } \\
\text { away from the split face } \\
\text { (10 pairs) }\end{array}$ \\
\hline$I_{100}$ & $15.0^{\circ}$ & $8.0^{\circ}$ \\
$D_{100}$ & $9.6^{\circ}$ & $4.5^{\circ}$ \\
$M_{100}$ & $1.16 \times 10^{-5} \mathrm{emu}$ & $0.725 \times 10^{-5} \mathrm{emu}$ \\
\hline
\end{tabular}

interval in the upper and middle $\mathrm{Y}$ zone $(11.5-95 \mathrm{~m})$ during which magnetite of variable but relatively coarse size was deposited, (5) deposition of finer magnetite between 95 and $100 \mathrm{~m}$ sub-bottom and a gradual coarsening, to a size comparable to that in the interval $11.5-95 \mathrm{~m}$, between 100 and $135 \mathrm{~m}$ sub-bottom, and (6) deposition of coarse magnetite below $135 \mathrm{~m}$ (Fig. 6).

Comparison of the rock-magnetic stratigraphies with the lithostratigraphy of Bouma, Stelting, et al. (this volume) indicates that major variations in the rock-magnetic parameters generally correspond to identifiable lithologic indicators and/or seismic reflectors (Fig. 6). This result tends to confirm that variations in the rock-magnetic parameters mirror changes in the overall sediment composition. 


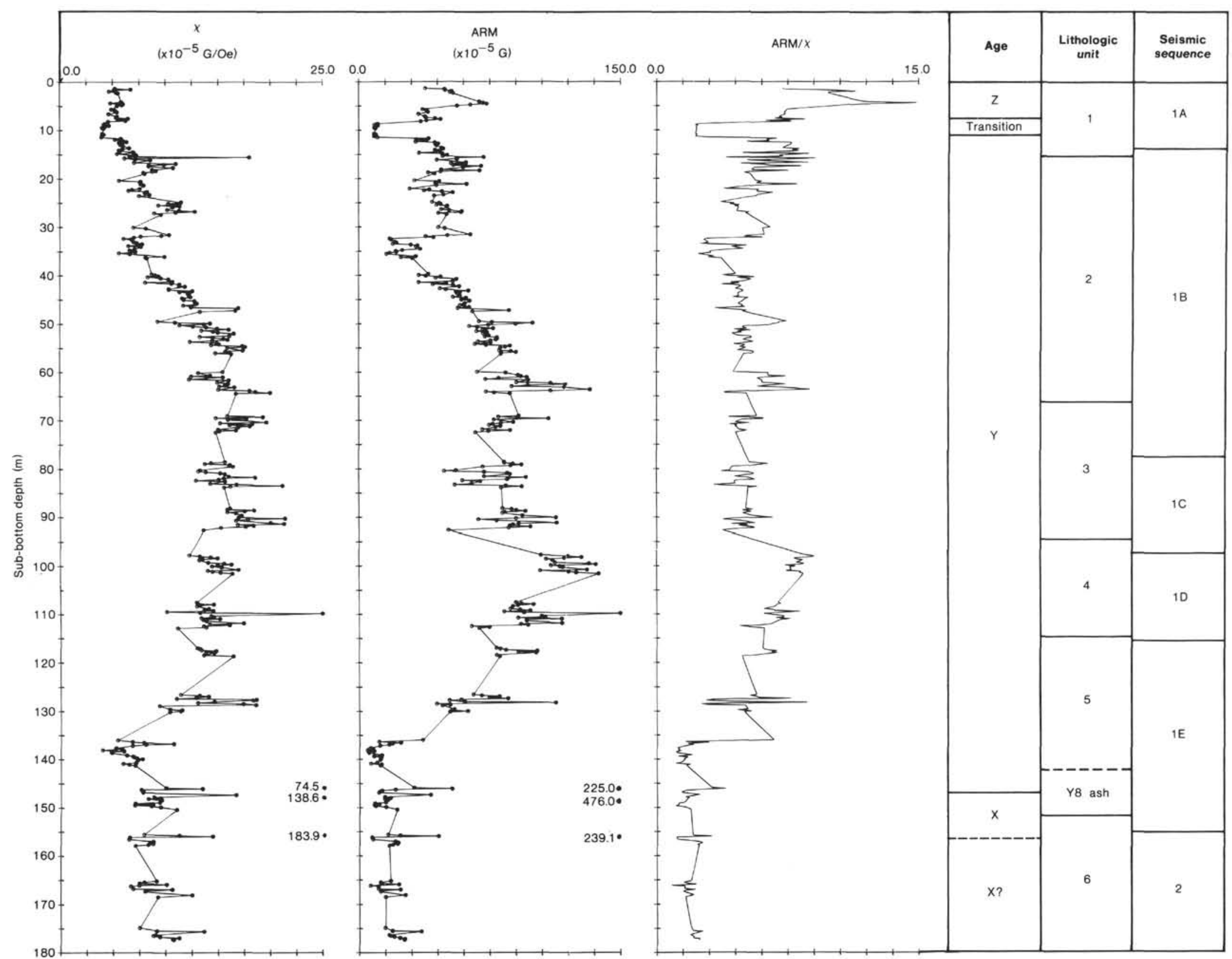

Figure 6. Plots of low-field susceptibility $\chi$ at a frequency of $1 \mathrm{kHz}$, anhysteretic remanent magnetization (ARM), and ARM/ $\chi$ ratio versus depth at Pigmy Basin. The lithology and seismic sequence log is from Bouma, Stelting et al. (this volume). Ericson zonation modified from Kohl (this volume). 

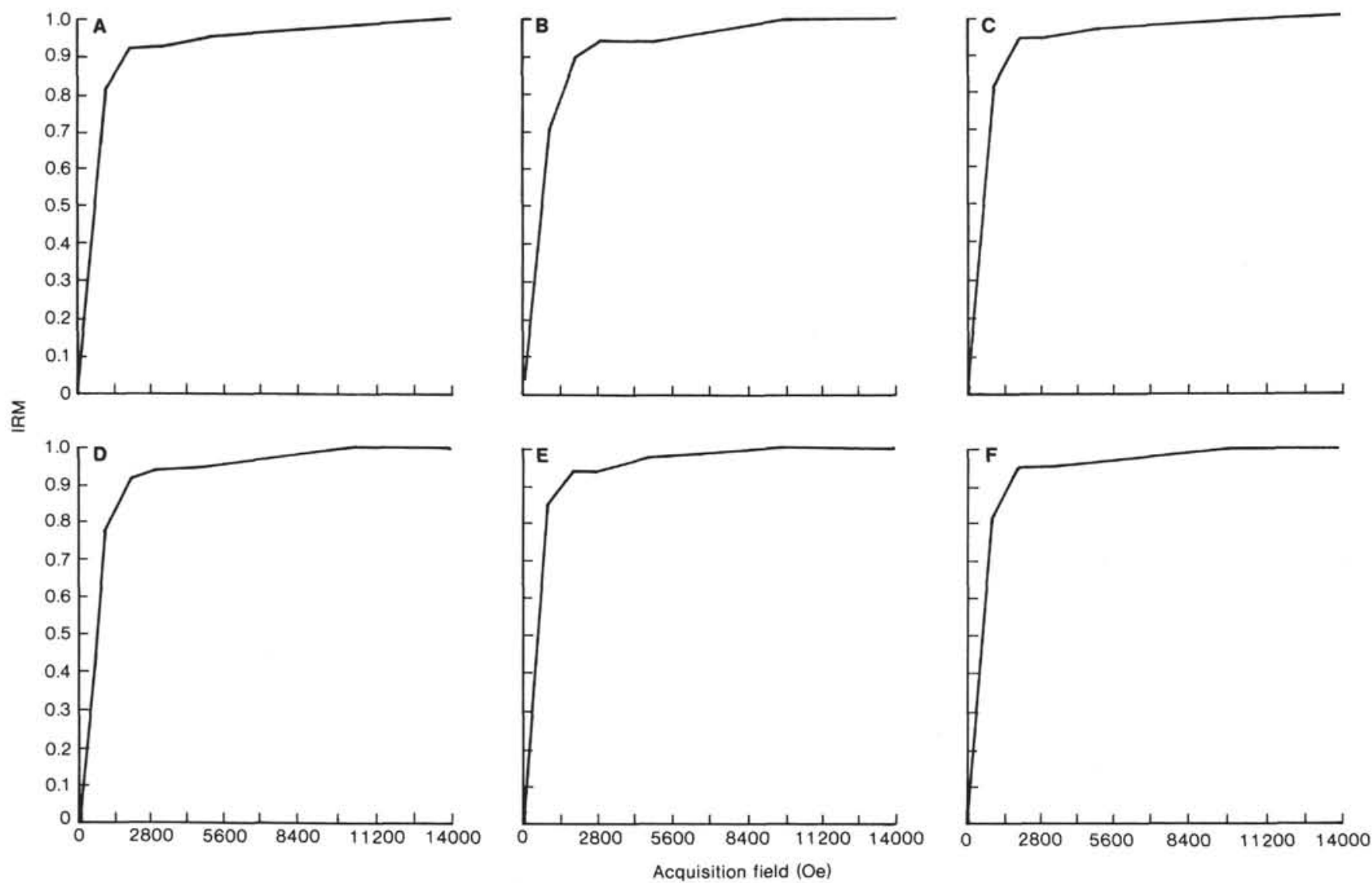

Figure 7. Representative IRM acquisition curves for Hole 619, Pigmy Basin. The samples approach saturation by 5000 Oe, indicating that the predominant magnetic carrier is probably magnetite or maghemite. A. Sample 619-1-1, 60-62 cm; B. Sample 619-3-1, 120-122 cm; C. Sample 619-1-6, 40-42 cm; D. Sample 619-3-3, 140-142 cm; E. Sample 619-1-5, 120-122 cm; and F. Sample 619-3-6, 100-102 cm.

\section{DISCUSSION AND CONCLUSIONS}

The paleomagnetic record of Pigmy Basin indicates that high-quality, high-resolution paleomagnetic records can be obtained in the Gulf of Mexico. Furthermore, the occurrence of a sequence of apparent geomagnetic excursions during the late Pleistocene is indicated by the inclination record and should provide an excellent basis for developing a high-resolution stratigraphic framework for the region.

The paleomagnetic results from the two different sampling methods compiled in Table 1 indicate that the coresplitting process has a demonstrable and adverse effect on the quality of the paleomagnetic records. In future studies, it is recommended that measurements be made on either whole-core samples prior to splitting or subsamples obtained from the center of the split core, rather than adjacent to the split face.

The paleomagnetic record deteriorates badly below $146 \mathrm{~m}$, indicating either core disturbance or a depositional process that produces disturbed sediments. NRM values are stable below $146 \mathrm{~m}$, but the vector values are considerably different for each of the samples measured at each level (Fig. 3). This observation is most consistent with the presence of convoluted or disturbed bedding rather than core disturbance. Core disturbance often produces large differences in samples from the same level, but the results are seldom stable upon AF demagnetization.

The shallowing of inclination values observed in Hole 619 has been observed in previous paleomagnetic investigations of HPC cores (e.g., Leg 73, Tauxe et al., 1983). Paleomagnetic studies of synthetic sediments consolidated in the laboratory indicate that irreversible shallowing of inclination values can occur as a result of compaction (Hall, 1983). Therefore, this trend in the inclination may be a postdepositional artifact rather than a syndepositional feature of the geomagnetic field.

A major goal of the rock-magnetic aspect of this study was to identify the rock-magnetic signature of glacialinterglacial cycles. The signature for the upper $140 \mathrm{~m}$ of section (Fig. 3) can be described as follows: (1) higher concentrations of magnetic material (higher values of $\chi$ and ARM) occur during glacial intervals (Ericson Zone Y) than during interglacials (Ericson Zone Z), (2) finer particles of magnetite (indicated by higher values of $\mathrm{ARM} / \chi)$ are deposited during interglacials than during glacials, and (3) coarse magnetite, indicated by lower values of $\mathrm{ARM} / \chi$, is deposited during the transition from glacial to interglacial intervals. However, the pattern observed below $146 \mathrm{~m}$ is not consistent with these interpretations (Fig. 6).

Two alternative hypotheses can be posed to explain the anomalous rock-magnetic results obtained below $146 \mathrm{~m}$ : 


\section{J. W. KING}

(1) Zone $\mathrm{X}$ and the $\mathrm{X}-\mathrm{Y}$ zone transitions are fundamentally different from $\mathrm{Z}$ one $\mathrm{Z}$ and the $\mathrm{Y}-\mathrm{Z}$ transition in the Gulf of Mexico region as a whole or (2) the local environment of deposition within Pigmy Basin was fundamentally different during Ericson Zone X. The second hypothesis is favored because of the sedimentological evidence of disturbed bedding. It is very likely that increased local diapirism occurred during this time interval and this local event overshadowed regional paleoenvironmental events. However, studies of additional sites in the Gulf of Mexico are necessary prior to rejecting the first hypothesis.

The observed correspondence between lithologic, seismic, and rock-magnetic variations shown in Figure 6 suggests that rock-magnetic parameters are valuable paleoenvironmental indicators. However, the record from Pigmy Basin appears to be influenced by both regional and local events rather than simply being a record of glacialinterglacial cycles.

\section{ACKNOWLEDGMENTS}

An earlier draft of this manuscript was reviewed by L. Tauxe and an anonymous reviewer.

\section{REFERENCES}

Bloemendal, J., 1983. Paleoclimatic implications of the magnetic properties of sediments from DSDP Site 514, Southeast Argentine Basin. In Ludwig, W. J., Krasheninnikov, V. A., et al., Init. Repts. DSDP, 71: Washington (U.S. Govt. Printing Office), 1097-1108.
Clark, H. C., and Kennett, J. P., 1973. Paleomagnetic excursion recorded in latest Pleistocene deep-sea sediments, Gulf of Mexico. Earth Planet. Sci. Lett., 19:267-274.

Ericson, D. B., and Wollin, G., 1968. Pleistocene climates and chronology in deep-sea sediments. Science, 162:1227-1234.

Freed, W. K., and Healy, N., 1974. Excursions of the Pleistocene geomagnetic field recorded in Gulf of Mexico sediments. Earth Planet. Sci. Lett., 24:99-104.

Hall, F. R., 1983. A study of the effects of consolidation (compaction) on the remanent magnetism of argillaceous sediments [MS thesis]. Lehigh University, Bethlehem, PA.

Kent, D. V., 1982. Apparent correlation of paleomagnetic intensity and climatic records in deep-sea sediments. Nature, 299:538-539.

King, J. W., Banerjee, S. K., Marvin, J., and Ozdemir, O., 1982. A comparison of different magnetic methods for determining the relative grain size of magnetite in natural materials: Some results from lake sediments. Earth Planet. Sci. Lett., 59:642-649.

Liddicoat, J. C., and Coe, R. S., 1979. Mono Lake geomagnetic excursion. J. Geophys. Res., 84:261-271.

Robinson, S. G., 1986. Mineral-magnetic stratigraphy of North Atlantic deep-sea sediments and its paleomagnetic significance. Spec. Publ. Geol. Soc. London.

Tauxe, L., Tucker, P., Petersen, N. P., and LaBrecque, J. L., 1983. The magnetostratigraphy of Leg 73 sediments. Paleogeogr., Palaeoclimatol., Palaeoecol., 42:65-90.

Zijderveld, J. D. A., 1967. A. C. demagnetization of rocks, analysis of results. In Collinson, D. W., Creer, K. M., and Runcorn, S. K. (Eds.), Methods in Palaeomagnetism: Amsterdam (Elsevier), pp. 254-286.

Date of Initial Receipt: 20 March 1985

Date of Acceptance: 10 October 1985 